\title{
Exploring Drivers of Nitrate Contamination of Drinking Water in an Arid Region of China
}

\author{
G. W. Huang ${ }^{1}$, H. Liu ${ }^{1}$, X. $\mathrm{Li}^{2}$, and M. Ma ${ }^{3}$ \\ ${ }^{1}$ Graduate School of Global Environmental Studies, Sophia University, 7-1, Kioicho, Chiyoda-ku, Tokyo, 102-8554, Japan \\ ${ }^{2}$ Cold and Arid Regions Environmental and Engineering Research Institute, Chinese Academy of Sciences, Lanzhou, 730000, China \\ ${ }^{3}$ School of Geographical Sciences, Southwest University, Chongqing, 400716, China
}

Received 8 December 2016; revised 30 July 2107; accepted 8 September 2017; published online 04 January 2019

\begin{abstract}
Nitrate contamination of groundwater is increasingly becoming a global concern due to its potential risks for human health. Fertilizer overuse is often thought to be the cause and a reduction in fertilizer use considered the most effective way of reducing contamination. The present study, however, presents the case of Zhangye City, Gansu Province, China, in which the nitrate contamination of underground sources of drinking water resulted from a combination of fertilizer overuse and a mismatch between the geological structure of farmland and the crop type cultivated upon it. In addition, a market-induced driver was identified for its role in accelerating the contamination process. This new evidence emphasizes that environmental pollution is often driven by multiple factors of great complexity, demonstrating that causes of environmental problems should be addressed and analyzed with a cross-sectoral perspective. Furthermore, this case revealed that Chinese cabbages cultivated in a drought-stressed region contained very high nitrate concentrations that exceeded Acceptable Daily Intake level, whereas tomatoes and cucumbers from the same region were shown to contain nitrate levels within the safe range. These findings are useful for developing a new policy framework for environmentally sound agricultural planning.
\end{abstract}

Keywords: aquifer, crops, drinking water, nitrate, Zhangye

\section{Introduction}

As the impact of human activities on the nitrogen cycle is significantly increasing, so are concerns regarding the fate of nitrate, which is a naturally occurring form of nitrogen and an integral part of the environmental nitrogen cycle. Although nitrate is an essential input for sustainable agriculture, nitrate contamination of groundwater is a growing concern worldwide as it can pose risks to human health. Nitrate is soluble in water and can easily pass through the soil to the groundwater table. It can persist in groundwater for decades accumulating to high levels as more nitrogen is used on the land surface every year.

In a number of countries there are strict limits on the permissible concentration of nitrate in drinking water and in surface waters. This limit is $50 \mathrm{mg} / \mathrm{L}$ in the EU and $44 \mathrm{mg} / \mathrm{L}$ in the USA (equivalent to 11.3 and $10 \mathrm{mg} / \mathrm{L}$ of nitrate- $\mathrm{N}$, respecttively). These limits are in accordance with WHO recommenddations established in 1970 and have been recently reviewed and reconfirmed (WHO, 2004). Nitrate-N concentration in natural groundwater is usually less than $2 \mathrm{mg} / \mathrm{L}$ (Mueller, et al., 1995).

Exposure to nitrates at levels above health-based risk val-

${ }^{*}$ Corresponding author. Tel: 81-3-3238-4667; Fax: 81-3-3238-4667.

E-mail address: huang@genv.sophia.ac.jp (G. W. Huang).

ISSN: 1726-2135 print/1684-8799 online

(C) 2019 ISEIS All rights reserved. doi: 10.3808/jei.201900409 ues may cause adverse health effects on infants (Shearer, et al., 1972; Dusdieker and Dungy, 1996). Babies less than three months old are particularly susceptible to the so-called blue baby syndrome caused by over-intake of nitrate. In two cases of blue baby syndrome reported in Wisconsin, USA, water samples collected from the local wells during the infants' illnesses contained nitrate- $\mathrm{N}$ concentrations of 22.9 and 27.4 $\mathrm{mg} / \mathrm{L}$ (Knobeloch, et al., 2002). Studies in Eastern Europe indicated higher rates of thyroid abnormalities in children ingesting water with high nitrate levels, as compared to children from areas with water nitrate- $\mathrm{N}$ concentrations of less than 10 mg/L (Van Maanen, 1994; Tajtakova, et al., 2006). Nitrate, when reduced to nitrite, reacts in the acidic environment of the stomach to form various nitrosating agents. These agents react with amines and amides from proteins, or sources such as medications, to form carcinogenic N-nitroso compounds, which could be a health risk to adults (Mensinga, et al., 2003). In addition, spontaneous abortions have been reported as being associated with drinking water from nitrate-contaminated private wells (Centers for Disease Control and Prevention, 1996). A recent study indicated that higher water nitrate intake was associated with several birth defects including neural tube defects, overall central nervous system defects, oral cleft defects, musculoskeletal defects and congenital heart defects (Brender, et al., 2013).

Although studies have found adverse health effects resulting from higher doses of nitrate, the current literature does not provide sufficient evidence of a causal relationship between 
exposure to high level of nitrate and adverse health effects. Further studies incorporating new methods of health impact assessment tailored to nitrate should be pursued, and risk analysis models such as the recent work by $\mathrm{Li}$, et al. (2017) for arid regions could be utilized.

Sources of nitrate contamination include fertilizers, the septic system, animal manure, and airborne nitrogen compounds released by industry and automobiles, which are deposited on the land as dry particles and through precipitation. In the target region of the present study there are a large number of simple pit latrines, which may also contaminate groundwater by leaching due to the lack of physical barrier between stored excreta and soil and/or groundwater. Considering the fact that almost half the global population now relies on groundwater for daily drinking water, contamination of groundwater will have serious and far-reaching consequences. More studies exploring the various drivers of nitrate contamination of the underground sources of drinking water from a cross-sectoral perspective are therefore justifiable.

Although there is considerable literature documenting the impact of agriculture with heavy nitrogen fertilization on nitrate accumulation in groundwater and vegetables in both developed and developing countries (Cantliffe and Phatak, 1974; Correia, 2010; Annette et al., 2015; Antonino, et al., 2015; Boris, et al., 2016), studies on the nitrate contamination of drinking water and agricultural crops are often conducted separately and lack sufficient attention to the link between the two. In addition to the overuse of fertilizers, other possible causes of nitrate contamination of groundwater and crops remain less explored. Studies on nitrate leaching modeling have considered soil tex-ture as well as cultivation methods or crop management, but are often confined to the local level and are focused on shallow groundwater (Moreels, et al., 2003; Li, et al., 2006). Therefore, these studies could not be directly used to assess drinking water quality if it is abstracted from a confined aquifer. As pointed out by the European Environment Agency in 2003, the problem of groundwater contamination by agricultural practices was an area lacking any progress in the EU (EEA, 2003) and the progress since then appears limited.

Considering the spatial heterogeneity and natural nitratereduction capacity of soil, the different nutrients requirements of different crops and the varied locations of drinking water wells, groundwater contamination by fertilizer may also exhibit high levels of heterogeneity. Therefore, although fertilizer overuse poses a major risk to public health, it should not be taken for granted that underground sources of drinking water would be degraded if there is excessive use of fertilizer; a multidisciplinary perspective is required for the identification of problems and their causes. In addition to drinking water, another primary pathway of human nitrate intake is vegetable consumption. Even if drinking water is safe in terms of nitrate contents, the risk of being exposed to high level of nitrate may remain high if there is a significant level of nitrate accumulation in vegetables. In the southern part of Zhangye City, the irrigation water for vegetable-cultivation is mainly abstracted from shallow wells, which are susceptible to nitrate contamination. The use of irrigation water with a high concentration of nitrate in addition to excessive fertilization can be considered a self-amplifying driver of nitrate contamination of water and crop. Therefore, it is desirable to study nitrate contents in both drinking water and vegetables together. There are many nutriational, environmental and physiological factors affecting nitrate uptake, translocation and accumulation in vegetables, and plant nitrate content is an outcome of imbalance between its net absorption and assimilation rates. Nitrogen fertilization, light intensity and the nitrate content of soil before or at harvest have been identified as the major factors influencing nitrate content in vegetables (Cantliffe, 1973, Santamaria, 2006). A study of 26 different vegetable types revealed that leaf vegetables (namely rocket, celery, parsley and spinach) contained higher levels of nitrate than bulb, root, shoot, inflorescence and tuber vegetables. Nevertheless, how nitrate contents in vegetables are affected by drought stress remains insufficiently studied.

In this study, we examine the issue of nitrate contamination of groundwater from a multidisciplinary perspective, considering the geological structure, agriculture, poor sanitation and indirect market influence. A household investigation of nitrate concentration in drinking water in an agricultural arid region of China was conducted in combination with multiple surveys including fertilizer use, spatial change in geological structure and crop types, Escherichia coli (E. coli) and market influence on farming. In addition, nitrate contents in some vegetables produced in the target region were also investigated. The main objective is to answer the question-"does where to cultivate what matter in regard to groundwater contamination by nitrate?". It presents a case in which drinking water contamination resulted from a combination of fertilizer overuse and a mismatch between agricultural land-use and geological structure. The identification of this new driver of nitrate contamination, as well as other related findings, are useful for better agricultural planning and for prioritizing where groundwater remediation should be taken seriously. Based on the findings from this study, a policy framework was presented for better managing agricultural practice in relation to the nitrate problem.

\section{Materials and Methods}

\subsection{Site Description}

The present study was conducted in Zhangye City, Gansu Province, China. The city is located in the middle reaches of Heihe River, which is the second largest inland river in China. The target region is characterized by a dry continental climate, with mean annual precipitation less than $200 \mathrm{~mm}$ and annual potential evaporation of $2000 \mathrm{~mm}$ or more. The renewable water resource per capita in Zhangye City is $1,250 \mathrm{~m} 3 / \mathrm{yr}$, just $5 \%$ of the world average. Since 2001 , approximately $50 \sim 60 \%$ of the annual total river discharge was diverted from the middle to the lower reaches of the river following regulations imposed by the Ministry of Water Resources of China (MWR). Consequently, groundwater abstraction for reuse in agriculture increased gradually to compensate for the reduced river water supply.

Apart from the downtown area, groundwater is the only source of drinking water in Zhangye City. The drinking water supply system in the rural areas of the city is generally one well 
per village. Groundwater is pumped to a water tower and delivered to each household through a pipeline by gravity. Moreover, $95 \%$ of villages surveyed in the present study have drinking water wells approximately $120 \mathrm{~m}$ deep.

The survey in 2015 was mainly focused on Ganzhou District, which includes the downtown area of the city, more than 30,000 hectares of corn seed farmlands, and 12,000 hectares of vegetable farmlands and is the central area of Zhangye Basin (Figure 1). Seed corn cultivation is the pillar of Ganzhou's agriculture, with Ganzhou producing one fifth of China's corn seeds and named by the Ministry of Agriculture of China as the nation's district for cultivating seed corn. Vegetable cultivation has been expanding in recent years in Ganzhou District due to increasing demand, and is positioned as a new strategy for further development by the local government.

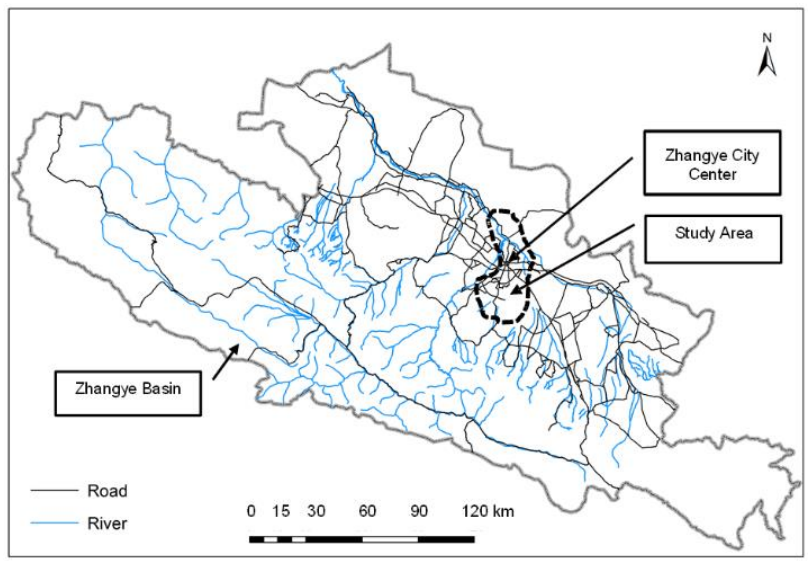

Figure 1. Zhangye Basin and study area.

\subsection{Sampling Methods}

The present study was carried out during the period July August 2015 and a targeted sampling method was adopted for investigating nitrate content in drinking water. The goal of this sampling was to focus on particular characteristics of a population that are of interest, which will best enable us to answer the research questions addressed. Although the overall sampling was not randomly conducted, this is not considered a weakness but a choice made in order to pursue exploratory or mixed methods research designs. For sampling size determination, the Cochran formula (Cochran, 1977) with finite population adjustment was employed as a criterion. The formula is given below:

$n=\frac{n_{0}}{1+\frac{n_{0}-1}{N}}, n_{0}=\frac{Z^{2} p(1-p)}{e^{2}}$

where $\mathrm{n}$ is the sample size, $Z^{2}$ is the abscissa of the normal curve that cuts off an area $\alpha$ at the tails ( $1-\alpha$ equals the desired confidence level), $e$ is the desired level of precision, $p$ is the estimated proportion of an attribute that is present in the population, and $N$ is the population size. The value of $Z$ is found using statistical tables, which contain the area under the normal curve. Since the target region, Ganzhou District, has 243 vil- lages, assuming $p=0.5$ (maximum variability) and taking a $95 \%$ confidence level and $\pm 10 \%$ precision, the resulting sample size is 69 . Following this guideline, we tested the drinking water quality in 66 villages, which can be divided into corngrowing-dominated villages and villages where commercial vegetables production was significantly developed. We also tested the drinking water quality in the downtown area of Zhangye City for comparison. In each village, we measured the nitrate concentration in the drinking water of three randomly selected households, and the mean was taken as the representative concentration for that village. Among all surveyed sites, $40 \%$ were located in vegetable-growing villages, $5 \%$ in urbanized areas, and the remaining $52 \%$ in corn-growing villages. Corn-growing villages are located in the northern part of the city while villages having large-scale commercial vegetable production are concentrated in the southern part of the city. Thus, the drinking water samples in this study were not normally distributed, and the number of samples was not evenly divided between the southern and northern areas. However, this was justifiable because our preliminary surveys in previous years found that drinking water in the northern part of the city had lower nitrate concentration and much less variation than that in the southern part. A research hypothesis that this study intended to validate was that drinking water quality in the target area was affected by crop selection. The distribution of sampling locations in the present study fits the purpose of the hypothesis validation.

Furthermore, for exploring the impact of pit latrines on drinking water quality, a survey of E. coli was conducted in drinking wells in 12 villages by the use of System EnSURE, manufactured by Hygiena International Limited, through a two-step six-hour-incubation process. Six samples were taken from corn-growing villages and another six from villages with large-scale vegetable production.

In addition to drinking water sampling, vegetables and corn plants were also sampled to test their nitrate contents. For agricultural crop sampling, a combination of "Typical Case Sampling" and "Confirming and Disconfirming Sampling" was adopted, because seed corn is the dominant crop and vegetables are known to be susceptible to high levels of nitrate. Sampling vegetables was undertaken to gain a better understanding of the total risk of nitrate over-intake and to confirm the current situation in the target region, not for statistical generalization. The objective of measuring the nitrate concentrations in corn plants, which was done by applying a so-called Late-Season Cornstalk Nitrate Test (LSCNT) developed at Iowa State University (Blackmer and Mallarino, 2000), was to judge the appropriateness of nitrogen fertilizer use. The rationale of this method is that corn plants deficient in nitrogen will usually remobilize stored nitrogen from the lower portions of the stalk and leaves to the developing grain, resulting in the lowest stalk nitrogen concentrations at the end of the season. As a result, corn plants taking more nitrogen than required to attain maximum yield accumulate nitrate in their lower stalks at the end of the season. On the basis of the measured nitrate concentration in the root segment of corn stalk, nitrogen fertilizer use can be classified into four categories as below: 
Low $(<250 \mathrm{ppm})$ : indicating a high probability that additional fertilizer or manure nitrogen would result in higher yields.

Marginal (250 - $700 \mathrm{ppm})$ : indicating that nitrogen availability is very close to the minimum amount needed to maximize grain yields.

Optimum (700 - 2000 ppm): indicating a high probability that the amount of soil, fertilizer, and manure nitrogen available during the growing season is sufficient to maximize profits for the producer.

Excessive ( $>2000 \mathrm{ppm})$ : indicating a high probability that the amount of fertilizer or manure nitrogen applied is greater than necessary to maximize profits for the producer for this production year.

Furthermore, interviews were conducted in 33 villages with farmers regarding the amount of fertilizer used annually per farmland unit. For the interview, the convenience sampling approach was adopted because it was not possible to obtain a list of all farmers in the target region from which to perform random sampling. Although the convenience sampling may suffer from biases, the information obtained is useful for supporting the judgment by LSCNT regarding over-fertilization. The nitrate concentration of drinking water was measured with the Horiba compact nitrate ion meter using an ion selective membrane (LAQUAtwin-B743). In order to measure the nitrate concentration in vegetables, $0.3-2 \mathrm{ml}$ of plant juice was extracted from the crop sample using a squeezer, and the nitrate concentration was measured with the Horiba compact nitrate ion meter for crops (LAQUAtwin-B741).

\section{Results and Discussions}

Figure 2 shows the variation of nitrate $\left(\mathrm{NO}_{3}{ }^{-}\right)$concentration in drinking water among the villages surveyed. Here, 55\% of the investigated sites recorded nitrate concentrations exceeding the WHO standard for drinking water, and 23\% showed concentrations more than two times the standard. The highest concentrations mainly occurred in villages where commercial vegetable farming has been developed to a large scale. By contrast, corn-dominated villages in the north exhibited low nitrate concentrations.

All drinking water nitrate concentration data were then divided into three groups: one for commercial vegetablegrowing villages, another for mainly corn-growing villages, and the third for places with a drinking water supply from standard water treatment plants. Figures $3-5$ show the histograms of these three groups. Since the measured nitrate concentrations in each group are not normally distributed, the nonparametric Kruskal-Wallis test, which compares three or more unmatched groups, was employed to determine whether there are any significant differences between the three groups. Because the degree of freedom is two and the selected signifycance level is 0.001 , the critical value is 13.816 according to the Chi-Square Table. The test resulted in $\mathrm{H}=44.83>13.816$ ( $p=1.84 \mathrm{E}-10<0.001)$, so that the null hypothesis is rejected and there is, therefore, a statistically significant difference among the three groups.

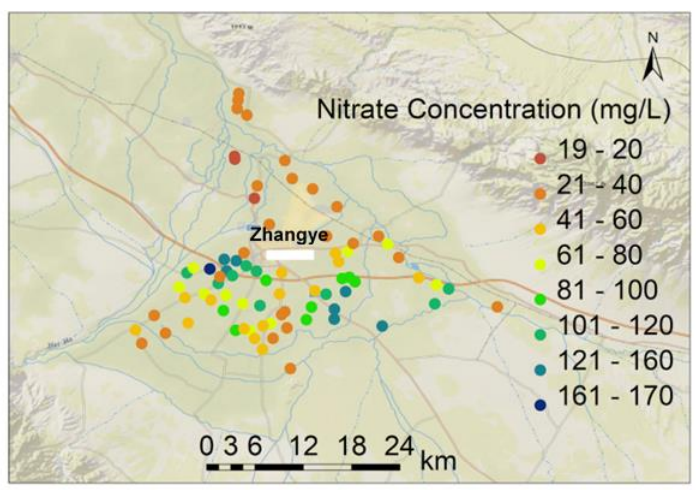

Figure 2. Spatial variation of nitrate concentration in drinking water.

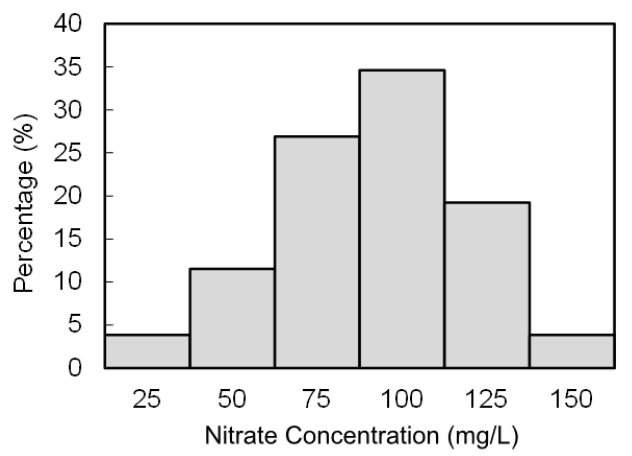

Figure 3. Histogram of measured nitrate concentrations in vegetable-growing villages.

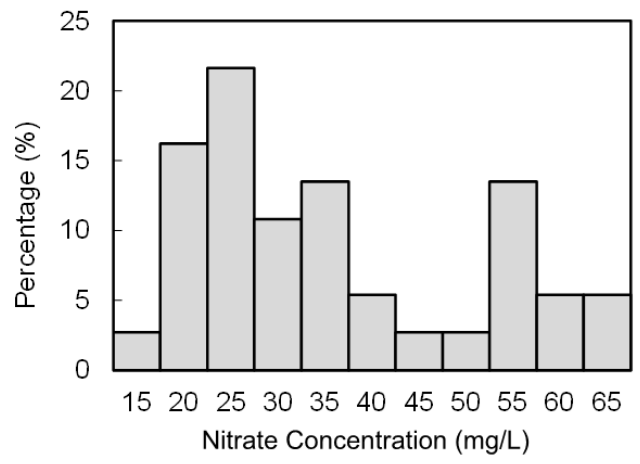

Figure 4. Histogram of measured nitrate concentrations in corn-growing villages.

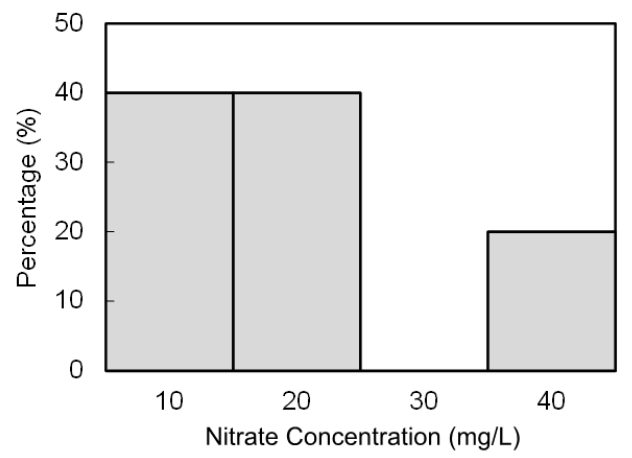

Figure 5. Histogram of measured nitrate concentrations in downtown area. 
Another distinction was made between the southern and northern villages, and the Mann-Whitney U test indicated significant differences in the drinking water nitrate concentrations between south and north.

The study conducted by Zhang et al. in $2001-2002$ (Zhang, et al., 2004) indicated that nitrate in the deep groundwater of the southern region derives largely from the mineralization of soil organic nitrogen, while the impact of fertilizers is secondary. In addition, Qin et al. in $2002-2004$ (Qin, et al., 2011) also confirmed that the groundwater quality was affected to some extent by farming. Compared to these previous studies, the present study revealed that the nitrate concentration of drinking water in the southernmost villages is relatively lower than in villages close to the urban center with commercial vegetable farming. This implies that nitrate in the deep groundwater approximately $10 \mathrm{~km}$ away from the city center is still largely dependent on soil organic nitrogen, but the impact of fertilizers has progressed and seriously degraded the drinking water in many southern villages close to the urban center.

As shown in Figure 6, the groundwater in the southern region is located in a single-layer, unconfined aquifer with coarse materials, whereas, in the northern region, a multilayered aquifer system with fine materials is observed. Due to the geological difference between the south and north, groundwater is often used to irrigate vegetable farmlands in the southern villages because of a higher availability of groundwater than river water.

Shi et al. (Shi, et al., 2011) reported that the actual water consumption of seed corn is $12,390 \mathrm{~m}^{3} / \mathrm{ha}$, whereas consumption for vegetable farming in open field and greenhouse are $21,045 \mathrm{~m}^{3} /$ ha and $20,280 \mathrm{~m}^{3} /$ ha, respectively. In 2014 , we conducted questionnaire surveys in eight villages in the region and visited 72 farmer households for interviews. One of the questions asked related the amount of fertilizer each household used. The result was that the average fertilizer use in seed corn fields was half that used in vegetable fields. In 2015, 33 villages were surveyed for annual fertilizer use. As shown in Figure 7, the annual nitrogen fertilizer use in the district ranges from 370 to $800 \mathrm{~kg} / \mathrm{ha}$, with more fertilizer used in the southern region than in the northern region. In some southern villages, fertilizer use for vegetables is double that used for corngrowing in some northern villages.

Figure 8 shows nitrate concentrations measured in the root part of corn stalk in villages surveyed in 2015. According to LSCNT, more than $90 \%$ of the sites are judged as having excessive fertilizer use. However, there are three villages in the northern region where the LSCNT shows the optimal use of fertilizer. The cornstalk nitrate test results and interview outcomes are double evidence that fertilizer use in the southern region is higher than in the northern region, due to differences in the fertilizer demands of different crops.

On the basis of these findings, the mechanism of drinking water contamination by nitrate in the southern region of Zhangye may be explained as follows.

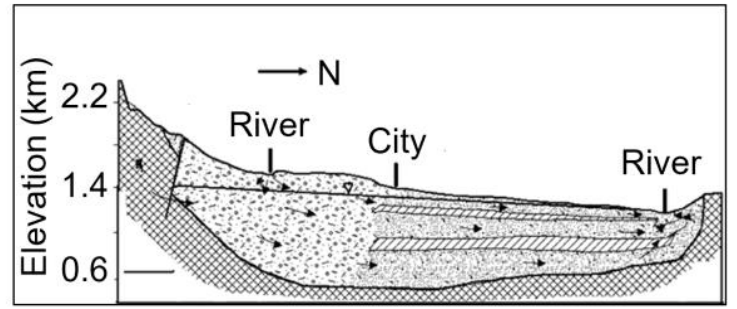

Figure 6. Change in geological structure from the south to north in Zhangye City.

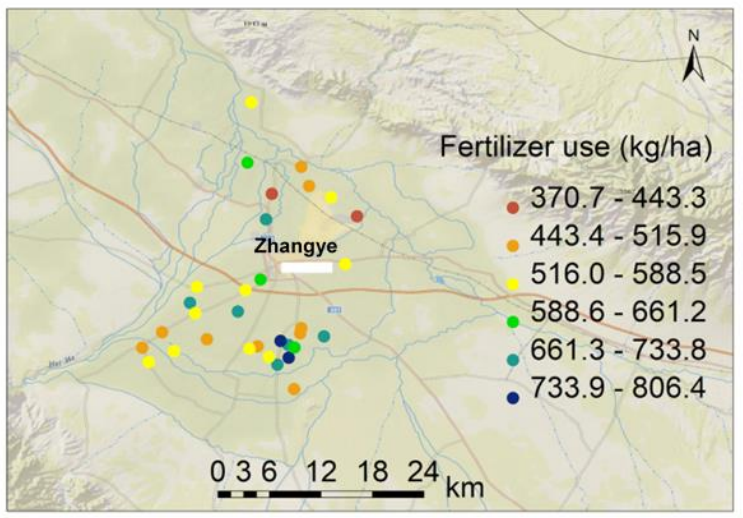

Figure 7. Spatial variation of nitrogen fertilizer use.

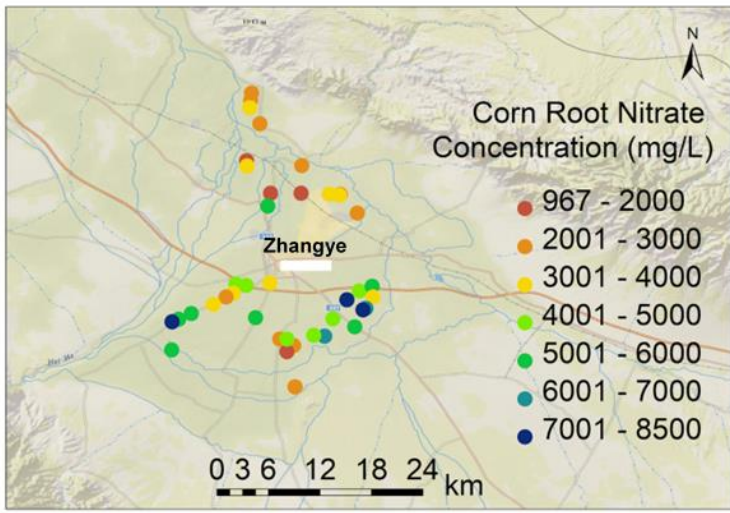

Figure 8. Nitrate contents in root part of corn stalk.

The infiltration capacity is greater in the southern region than in the northern region of the city, as is the amount of groundwater available to agriculture owing to differences in the geological structure of the aquifer. The higher availability of groundwater favors commercial vegetable farming in the southern region as vegetable production consumes more water than corn cultivation. Due to the increased irrigation water use and the excessive fertilizer application demanded by vegetables, nitrate leaching in the single-layered aquifer in the southern region reaches deeper, where the groundwater is withdrawn for drinking. By contrast, the three-layered aquifer system in the northern area prevents nitrate from reaching the confined groundwater, where drinking water is abstracted. The relatively lower use of water and fertilizer in the northern villages also plays a role in reducing nitrate leaching. 
Since the flow direction of groundwater in the Zhangye basin is generally from southeast to northwest, a question of whether the northern region would be affected by the contamination occurring in the southern region arises. In other words, why did the contamination of upstream groundwater not affect the groundwater downstream? According to the study by Feng (2008) using environmental isotope analysis and CFC dating, the confined groundwater below $100 \mathrm{~m}$ in the northern and southern regions near the urban center is separately recharged by water coming from the Qilian Mountain via bedrock crevice. The study by Zhang (2008) also confirmed that there is groundwater recharge through the deep faults of the Qilian Mountain in the Northern part of the Zhangye Basin. Therefore, the groundwater in the northern region at a depth of $120 \mathrm{~m}$, where groundwater is pumped up for drinking purposes, would not be directly affected by the groundwater contamination in the southern region since it is not connected to the deep groundwater in the south.

From 2010 to 2015, with the exception of 2013, the nitrate concentration of drinking water was measured during the summer in Guojiabao village, which is located in the southern region of Ganzhou district. Agriculture in Guojiabao village is dominated by vegetable production such as Cabbage, Cauliflower and Chinese cabbage. As shown in Figure 9, the nitrate concentration was already above the WHO standard in 2010 , and became much worse by 2015 . It is clearly seen that the nitrate concentration increased more from 2012 to 2015 than from 2010 to 2012 , indicating that the contamination has been accelerated recently.

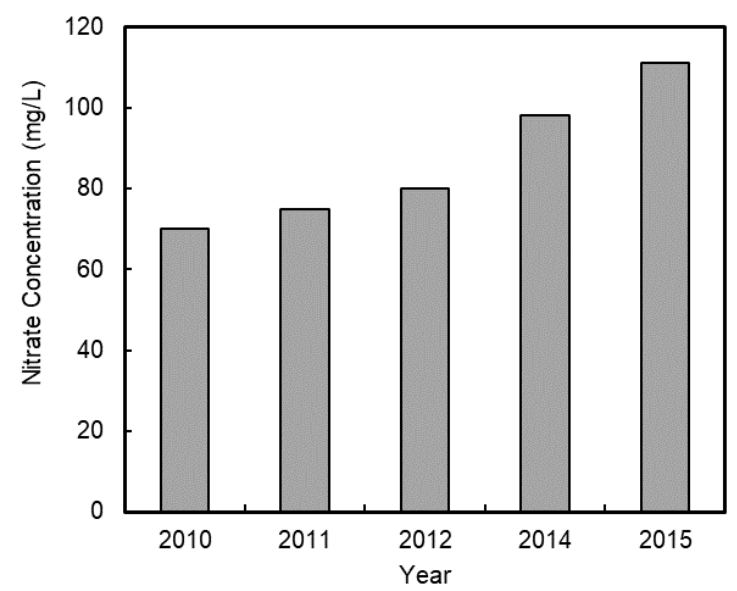

Figure 9. Change of nitrate concentration in drinking water with time in Guojiabao village.

In 2015, five types of vegetables cultivated in the southern region of Ganzhou District were sampled to measure their nitrate contents. These comprised Chinese cabbage, tomato, pepper, onion, and cucumber. As shown in Figure 10, Chinese cabbages contained very high levels of nitrate, with the lowest measurement being $4,900 \mathrm{mg} / \mathrm{kg}$, whereas tomato and cucumber demonstrated nitrate levels below the upper limit of what is considered safe as far as nitrate intake is concerned. Since the vegetables are mainly irrigated with groundwater, it can be asserted that the high level of nitrate accumulation in crops such as Chinese cabbage can be attributed to both overapplication of fertilizer and the use of contaminated groundwater for irrigation. Nevertheless, vegetables such as tomato and cucumber have shown a low level of nitrate assimilation.

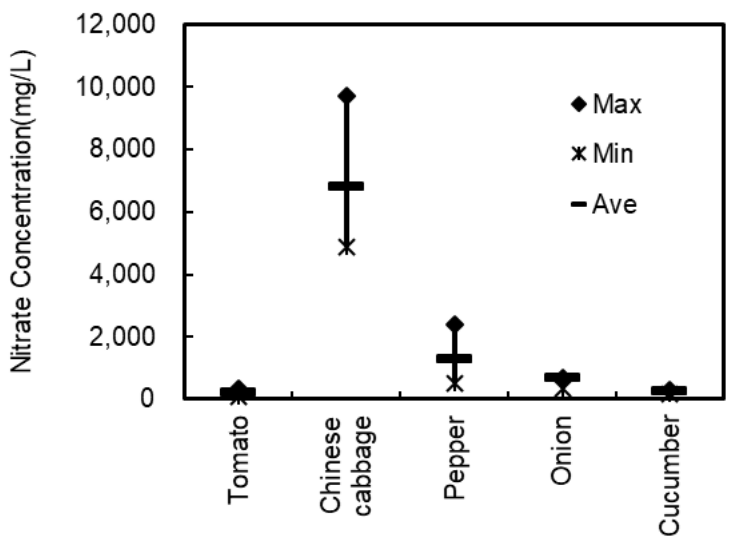

Figure 10. Nitrate contents in vegetables.

An Acceptable Daily Intake (ADI) for nitrate of $3.7 \mathrm{mg} / \mathrm{kg}$ bw/day, equivalent to $222 \mathrm{mg}$ nitrate per day for a $60 \mathrm{~kg}$ adult, was established by the European Commission's Scientific Committee on Food (SCF), and was reconfirmed by the Joint FAO/WHO Expert Committee on Food Additives (JECFA) in 2002. The USA Environmental Protection Agency (EPA) Reference Dose (RfD) for nitrate is $1.6 \mathrm{mg}$ nitrate nitrogen $\mathrm{kg}^{-1}$ bodyweight (bw) per day (equivalent to approximately $7.0 \mathrm{mg}$ $\mathrm{NO}_{3}^{-} \mathrm{kg}^{-1}$ bw per day).

According to the Chinese nutrition recommendations, a $300-500 \mathrm{~g}$ daily consumption of vegetables is desirable. Compared with the current ADIs, the ingestion of $300 \mathrm{~g}$ of raw vegetables with a nitrate concentration of $4900 \mathrm{mg} / \mathrm{kg}$ will lead to an intake of $1470 \mathrm{mg} \mathrm{NO}_{3}{ }^{-}$. Consuming this item alone, for a person of $60 \mathrm{~kg}$, would exceed the ADI for nitrate by more than six times. A pioneering study (van Velzen, et al., 2008) indicated that nitrate from vegetables, whether cooked or uncooked, is absorbed highly efficiently, resulting in an absolute nitrate bioavailability of around $100 \%$. Another study (Hunault, et al., 2009) showed that the bioavailability of nitrate was $95-98 \%$ under fasting conditions. Therefore, it is likely that the risk of nitrate over-intake has spread from drinking water to vegetable consumption in the target area of this study.

Furthermore, E. coli was detected in drinking wells in all villages surveyed. Although the highest level (CFU/mL: $100-$ 200) was found in a vegetable-growing village, statistically significant differences in E. coli levels between the two types of villages, corn-growing and vegetable-growing, were not observed. This implies that although pit latrines have contaminated groundwater, the degree of impact in the two types of villages may be considered similar to each other. As a result, the difference in nitrate concentration between the two types of villages could not be attributed to poor sanitation.

From a water-saving point of view, Zhangye City is not a suitable place for vegetable production because of the high 
water consumption of vegetables. As a matter of fact, seed corn cultivation was promoted in Zhangye City in order to save water, and became the dominant crop in 2001. However, corn production in China reached a record high in 2012. As a result, in 2015 China reduced the temporary purchase and storage price of corn by approximately $10.7 \%$ for the first time since the implementation of the temporary purchase and storage policy (Zhao and Cheng, 2015). This may be viewed as a sign that China's corn market is reaching a turning point. Indeed, the corn cultivation area in Ganzhou district was reduced by $32 \%$ in 2014 . The main vegetable production bases in China are all located in the east, where weather often adversely affects production from July to September. By contrast, the weather in Zhangye City from July to September is characterized by sufficient sunlight and large diurnal air temperature variations that are ideal for vegetable cultivation. Therefore, there is a market mechanism for Zhangye City to further promote vegetable production to meet demands outside of the region. Furthermore, income from vegetable cultivation is higher than from corn cultivation. Considering that vegetable cultivation is a new developmental strategy in Zhangye City, the results of the present study suggest that the city should conduct a comprehensive investigation to identify the optimal sites for environmentally sound development of the vegetable industry. In light of the findings from the present study, a policy framework for better environmental management in relation to agriculture is proposed below.

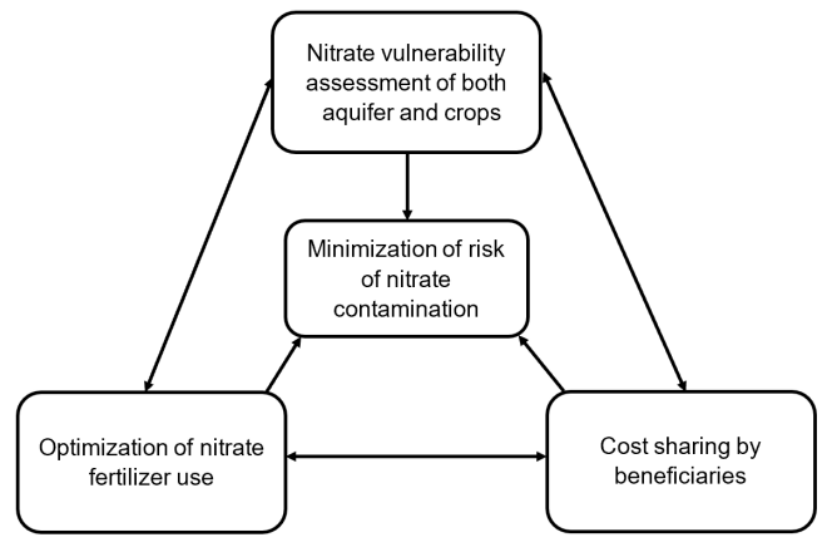

Figure 11. Nitrate contents in vegetables.

To minimize the risk of nitrate contamination, agricultural development must be preceded by vulnerability assessment of both aquifer and crops to nitrate contamination in combination with the optimization of fertilizer use. Considering the fact that large-scale agricultural development is often driven by market demand and not the need of local farmers, a 'cost-sharing by beneficiaries' scheme for environmental protection and remediation of agricultural sites should be designed. This scheme, could involve price setting, which is directly paid by consumers, tax allocations to the local government from the central government, or by compensation from those regions where agricultural product consumption is concentrated. Through the integration of vulnerability assessment, fertilization optimization and such a cost-sharing scheme (Fig. 11), both envi- ronment and public health would be better protected. This policy framework could also serve as a driver to promote further studies on the payment for ecosystem services.

\section{Conclusions}

Field investigations reveal that nitrate contamination of drinking water has progressed to a serious degree in a large number of vegetable-growing villages in Ganzhou District, Zhangye City. Mismatch between agricultural crop and site characteristics is identified as an amplifying driver of nitrate contamination in relation to excessive fertilization, which is the direct cause of groundwater contamination. This amplifying driver works at two levels. At the local level, the contamination caused by the overuse of fertilizers was worsened by cultivating fertilizer-demanding vegetables in areas of relatively high permeability. At the national level, the market-demand for vegetables from coastal cities promoted large-scale vegetable production in this ecologically vulnerable region. A lesson learned from the present study is that agricultural planning should not just consider market demand and the optimal use of water and fertilizers for crops, but also take into consideration local geology and its suitability in regard to crop type in order to achieve a best match between site characteristics and crop type. The negative impact of fertilizer overuse may be amplified under unfavorable site conditions, but would be lessened by favorable site conditions. Therefore, the present study highlights the necessity to develop a new framework for integrative planning of agricultural land use to minimize the negative impacts of agriculture. The field survey also shows that Chinese cabbages produced in the surveyed area contain nitrate at levels far higher than those deemed acceptable, whereas nitrate levels in tomatoes and cucumbers from the area were lower than the upper limit of what is considered to be safe. Although such a finding may not carry much weight by itself, it confirmed that vegetables produced under dry climate conditions have different nitrate assimilative capacities according to vegetable type. This suggests that the nitrate contamination in this region might be alleviated via crop structure optimization.

\section{References}

Fabro, A. Y. R., Ávila, J. G. P., Alberich, M. V. E., Sansores, S. A. C., and Camargo-Valero, M. A. (2015). Spatial distribution of nitrate health risk associated with groundwater use as drinking water in Merida, Mexico. Appl. Geogr.. 65, 49-57. https://doi.org/10.1016/ j.apgeog.2015.10.004

Antonino P., Gioacchino C., and Rocco F. (2016). Groundwater nitrate risk assessment using intrinsic vulnerability methods: A comparative study of environmental impact by intensive farming in the Mediterranean region of Sicily, Italy. J. Geochem. Explor.. 156, 89-100. https://doi.org/10.1016/j.gexplo.2015.05. 002

Blackmer, A.M. and Mallarino A.P. (2000). Cornstalk testing to evaluate nitrogen management. Iowa State University, Extension Publication.

Rebolledo, B., Gil, A., Flotats, X., and Sánchez, J. Á. (2016). Assessment of groundwater vulnerability to nitrates from agricultural sources using a GIS-compatible logic multicriteria model. J. Environ. Manage., 171, 70-80. https://doi.org/10.1016/j. jenvman.2016.01.041 
Cantliffe, D. J. and Phatak S. C. (1974). Nitrate accumulation in greenhouse vegetable crops. Can. J. Plant Sci., 1974a, 783-788. https://doi.org/10.4141/cjps74-132

Correia, M., Barroso, Â., Barroso, M. F., Soares, D., Oliveira, M. B. P. P., and Deleruematos, C. (2010). Contribution of different vegetable types to exogenous nitrate and nitrite exposure. Food Chem.. 120(4), 960-966. https://doi.org/10.1016/j.foodchem.20 09.11.030

Cochran, W. G. (1977). Sampling techniques, 3rd ed., John Wiley \& Sons, Inc., New York, United States.

Dusdieker L.B. and Dungy C.I. (1996). Nitrates and babies: A dangerous combination. Contemporary Pediatrics, 13, 91-102.

Feng, J. X., Ding, H. W., Chen, J. S., Yao, J. L., and Jiang-Hai, H. E. (2008). Study on the causes resulting in groundwater level rise in ganzhou city and its peripheral regions. Arid Zone Res., 25(4), 470477 (in Chinese).

Gangolli, S. D., Pa, V. D. B., Feron, V. J., Janzowsky, C., Koeman, J. H., Speijers, G. J., Spiegelhalder B., Walker R., and Wishnok J. (1994). Nitrate, nitrite and N-nitroso compounds. Eur. J. Pharmacol. (Environ. Toxicol. Pharmacol. Sect.), 1, 1-38. https://doi.org/10. 1016/0926-6917(94)90022-1

Knobeloch L., Salna B., and Hogan A. (2002). Agricultural nitrogen balance and water quality in the UK. Soil Use Manage., 18(4), 363369. https://doi.org/10.1079/SUM2002145

Li, C., Farahbakhshazad, N., Dan, B. J., Dinnes, D. L., Salas, W., and Mclaughlin, D. (2006). Modeling nitrate leaching with a biogeochemical model modified based on observations in a rowcrop field in Iowa. Ecol. Model.. 196, 116-130. https://doi.org/ 10.1016/j.ecolmodel.2006.02.007

Mensinga T.T., Speijers G.J.A., and Meulenbelt J. (2003). Health implications of exposure to environmental nitrogenous compounds. Toxicol. Rev., 22, 41-51. https://doi.org/10.2165/0 0139709200322010-00005

Mueller, D. K., Hamilton, P. A., Helsel, D. R., Hitt, K. J., and Ruddy, B. C. (1995). Nutrients in ground water and surface water of the united states - an analysis of data through 1992. U.S. Geological Survey Water Resources Investigations Report. 95-4031.

Moreels, E., Neve, S. D., Hofman, G., \& Meirvenne, M. V. (2003). Simulating nitrate leaching in bare fallow soils: a model comparison. Nutr. Cycling Agroecosyst., 67, 137-144. https://doi.org/10.1023/ A:1025526802717
Qin, D., Qian, Y., Han, L., Wang, Z., Li, C., and Zhao, Z. (2012). Assessing impact of irrigation water on groundwater recharge and quality in arid environment using CFCs, tritium and stable isotopes, in the Zhangye Basin, Northwest China. J. Hydrol., 405, 194-208 https://doi.org/10.1016/j.jhydrol.2011.05.023

Shearer, L. A., Goldsmith, J. R., Young, C., Kearns, O. A., and Tamplin, B. R. (1972). Methemoglobin levels in infants in an area with high nitrate water supply. Am. J. Public Health, 62(9), 1174. https://doi.org/10.2105/AJPH.62.9.1174

Shi M., Wang L., and Wang X. (2011). A study on changes and driving factors of agricultural water supply and demand in Zhangye after water reallocation of the Heihe River. Resources Science, 33(8), 1489-1497 (in Chinese).

Tajtáková, M., Semanová, Z., Tomková, Z., Szökeová, E., Majoros, J., Rádiková, Z., Seböková E, Klimes I., and Langer P. (2006). Increased thyroid volume and frequency of thyroid disorders signs in schoolchildren from nitrate polluted area. Chemosphere, 62(4), 559-564. https://doi.org/10.1016/j.chem osphere.2005.06.030

Ward M.H. (2009). Too Much of a Good Thing? Nitrate from Nitrogen Fertilizers and Cancer. Rev. Environ. Health, 24(4), 357-363. https://doi.org/10.1515/REVEH.2009.24.4.357

Van Maanen J.M., Van Dijk A., Mulder K., De Baets M.H., Menheere P.C.., Van der Heide D., Mertens P.L., and Kleinjans J.C. (1994). Consumption of drinking water with high nitrate levels causes hypertrophy of the thyroid. Toxicol. Lett., 72(1-3), 365-374. https:// doi.org/10.1016/0378-4274(94)90050-7

WHO. (2004). Rolling Revision of the WHO Guidelines for DrinkingWater Quality. World Health Organization.

Zhang C.Y., Wang Z., and Cheng X.D. (2004). Studies of nitrogen isotopes in sources of nitrate pollution in groundwater beneath the city of Zhangye. Journal of Arid Land Resources and Environment, 18 (1), 79-85.

Zhang H.S., Zheng Y., and Cui Z.Q. (2008). Cause for the rise of the groundwater level in the Ganzhou urban district and its surroundings, Zhangye City, Gansu, China and countermeasures for the prevention and control of its induced geohazards. Geological Bulletin of China, 27(3), 404- 413 (in Chinese).

Zhao Y. and Cheng Q. (2015). Temporary storage policy for maize in Chiina. Agricultural Overlook, 11, 1-5 (in Chinese). 